\title{
Process of Gate Keeping in Media: From Old Trend to New
}

\section{Prof. Ghulam Shabir}

\author{
Ph.D (Pak), Post-Doc(U.K), Chairman, Department of Media Studies \\ The Islamia University Bahawalpur, Pakistan \\ ghulam.shabir@iub.edu.pk
}

\section{Ghulam Safdar}

M.Phil (Researcher), Department of Media Studies

The Islamia University of Bahawalpur, Pakistan

safdarsting@gmail.com

Muhammad Imran

M.Phil (Researcher), Department of Media Studies

The Islamia University of Bahawalpur

imranmona3@gmail.com

Asad Mumtaz

M.Phil (Researcher), Department of Media Studies

The Islamia University of Bahawalpur asadmumtazseyal@gmail.com

Ashraf Ali Anjum

M.Phil (Researcher), Department of Media Studies

The Islamia University of Bahawalpur, Pakistan

\section{Doi:10.5901/mjss.2015.v6n1s1p588}

\section{Abstract}

Mass media is has playing significant role in strengthening the society, promoting knowledge, globalizing the world and disseminating the information. The study presents the importance of gate keeping. The objective of the study was to know about the different models of gate keeping described by the different media scientists from early age to present. Media gathers information from all over the world, which can not publish, broadcast or telecast as it is because there is very little time and space, so every form of media has to define its content. The process by which this practice is done, called gate keeping. Through this process information is filtered for dissemination. The quantitative methodology used for this study. Data is gathered from early gate keeping model to latest model. The study concluded that Gate keeping is a selection process in which all the information is organized by level of importance and interest. The gatekeeper or gatekeepers fix on which information is relevant after sorting it out in a hierarchy that determines what they need. Information from important topics, controversial issues, and contemporary news stories has a higher tendency of being selected. Moreover, the gatekeeper alone can't decide how the information is sorted, for this purpose there are many gate keepers who determine which information will be pass out to People, a gatekeeper is always having its own influences like social, cultural, ethical and political.

Keywords: Content, Gate keeping, Filtering, Mass media, Forces.

\section{Introduction}

Mass media is has playing significant role in strengthening the society, promoting knowledge, globalizing the world and disseminating the information. It has become as necessary as food and clothing. In fact, media is shaping our lives. Today, youth is strongly influenced by media, teenagers and children wish to follow the people, who get recognized and do what they do to get noticed, thus media affects people's perspective. Media can be considered as "watch dog" of 
democracy, society, national integration, people's personal information and ideology of the country. Mass media is in charge of information, education, entertainment, advertising and correlation of parts of society. Different types of mass media gathered information from all over the world, which can not publish, broadcast or telecast as it is because there is very little time and space, so every form of media has to define its content. The process by which this practice is done, called gate keeping. Through this process information is filtered for dissemination, It occurs at all levels of the media structure from the reporter to the editor in print media or reporter to director news in electronic media.

Gate keeping is a selection process in which all the information is organized by level of importance and interest, some time a person and few times a group determine how much of that information gets published or on aired. The gatekeeper or gatekeepers fix on which information is relevant after sorting it out in a hierarchy that determines what they need. Information from important topics, controversial issues, and contemporary news stories have a higher tendency of being selected since it will have a greater audience than articles that could risk a loss of interest. However, the gatekeeper alone can't decide how the information is sorted, for this purpose there are many gate keepers who determine which information will be pass out to People, a gatekeeper is always having its own influences like social, cultural, ethical and political.

Gate keeping is found in multiple fields of study, including communication studies, journalism, electronic media, social networks, political science, and sociology. Through this process the unwanted, sensible and controversial information's are removed which helps to control the society or a group and letting them in a right path. Mass media plays its role as mother in house plays the vital role and decides what their kid's needs and what should avoid. In Print Media editor and in electronic media director news play vital role and decides which news will be published, telecast or broadcast. The questions of this research paper are; how the media play its role as gatekeeper of society, what's its process in Pakistan, either traditional or unconventional.

\section{Literature Review}

\subsection{History and Evaluation of Gate keeping theory}

Before put some light on the topic and start the discussion, it will be good to trace the gate keeping in the history of man. Process of gatekeeping started right from the beginning of interpersonal communication. As Allah has give us knowledge according to our capacity and need, there was always some information was left to discover. Learn was the first divine massage, which paves the way of knowledge. Filtering of information is innate to man because it is his primary goal as human being. Individual forwarded the selective, controlled and edited information to others. This process kept going and then in 1922, Robert Park identified the concept, which yet to be given a theoretical name. Park explains the process "out of all of the events that happen and are recorded every day by correspondents, reporters, and the news agencies, the editor chooses certain items for publication which he regards as more important or more interesting than others. The remainder he condemns to oblivion and the wastebasket. There is an enormous amount of news 'killed' every day".

\section{Discussion}

\subsection{Kurt Zadek Lewin's Work}

Formally, gate keeping was identified in 1943 by Kurt Zadek Lewin through his research. Lewin was a great German Psychologist and pioneer in Social Psychology. His studies are more based on to understand a person's own world, physical, mental and social through frequent conversation between his pre-memories, desire and his goals. Working during World War II, Kurt Lewin conducted field research initially among Midwestern housewives to decide how to effectively change their families' food consumption during this time of war.

Lewin recognized that for food to go from a store or a garden to the dining table, there were various decisionmaking processes it had to pass on the way there it a time when men were thought to control all household decisions. Lewin found that food does not move by its own force, entering or not entering a channel and moving from one section of a channel to another are affected by a 'gatekeeper'. The gatekeeper in this case was typically the housewife or sometimes a maid in more well off households. Lewin's research demonstrated that not all members of a family have equal weight in making household food decisions, and that the wife, who typically shops for and prepares the food controls the gates, based on a variety of considerations. 


\subsection{David Manning White's Contribution}

Gatekeeping was officially applied to news in 1950 by David manning white, David manning White a friend and class fellow of Lewin and student of Wilbur Schramm looked at the factors an editor takes into consideration when deciding which news will make the paper and which news will not.

David White took Schramm's "source - message - receiver" approach to mass communication research, the dominant paradigm and one that fits adequately with the "channel" theory of gate keeping. He contacted an editor, a man in his mid-40s with 25 years of experience, whom he calls "Mr. Gates". The editor retained all copy that he rejected from the paper. After his shift, made notes on why that story was rejected, assuming he could still remember the reason. David White wanted to know if these are subjective decisions based on the editor's own set of experiences, attitudes and expectations. He found that rejections could be classified in two ways:

1. Rejecting based on not being worthy of being reported.

2. Rejecting based on duplicate of other reports on the same thing.

These considerations fit with what we call news norms today. However, Mr. Gates also admitted to preferring political news to other types, trying to avoid sensationalism, not liking suicide stories. He did not like giving page space to a scandal that had been going on in the Catholic Church at the time.

Figure 1: David Manning White's Model

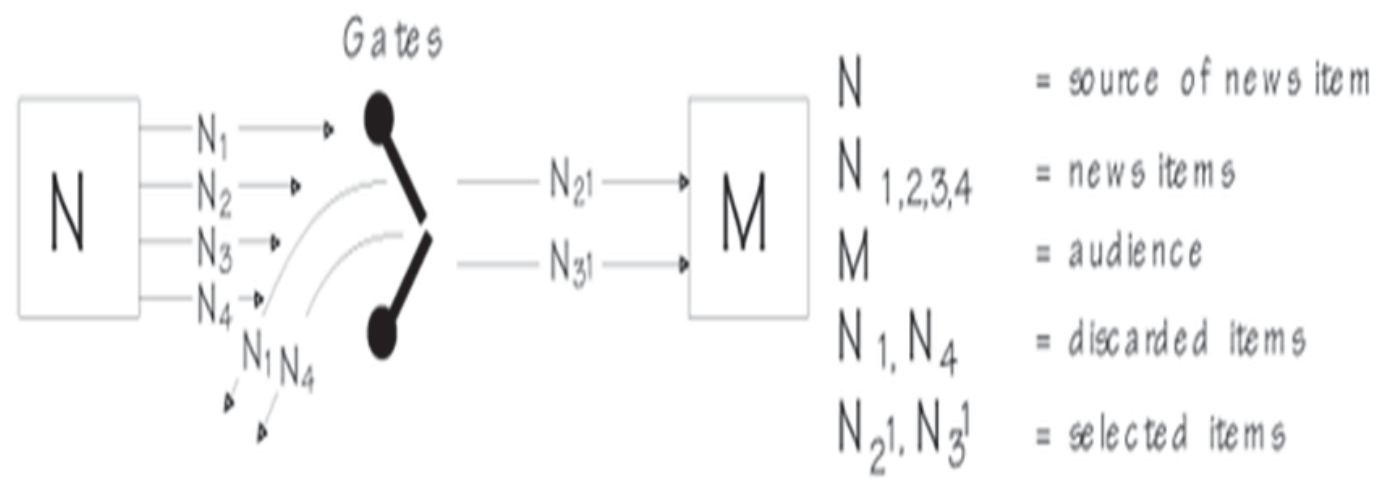

\subsection{Westley \& MacLean's Contribution}

In 1953, another Admirer of Kurt Lewin, Theodore Newcomb presents a co-orientation model, which was modified by his students Bruce Westley and Malcolm MacLean, They introduced "C" the gatekeeper into mass communication research and influenced by Lasswell's "who says what through what channels to whom with what effect." Their model remained a part of the dominant paradigm in mass communication research for decades. The most fundamental improvement to early gate keeping theories of mass communication introduces the notion of multiple gatekeepers who control various functions along the news process.

Figure 2: Westley \& MacLean's Model

\section{Westley and MacLean's Model of Communication}

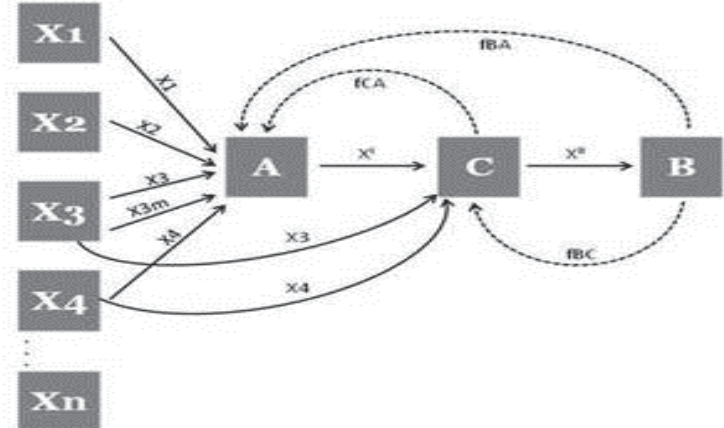




\subsection{Pamela Shoemaker's Contribution}

Criticism and development of the gatekeeper theory going on, every decade a new research published on that particular concept of, than after more than fifty years after White's Mr. Gates study, in 2001, Pamela Shoemaker, Martin Eichholz, Eunyi Kim, and Brenda Wrigley studied the forces in news gate keeping in relation to coverage of Congressional bills. Forces may be newsworthiness, prominence, education, political ideology, work experience, ethnicity, gender or behavior.

Shoemaker's 88-page book, Gate keeping theory which has been used as a basis for other publications provided a useful history of the theory, the process, and how gate keeping is applied at the individual, communication routine, organizational, and institutional level. Moreover, it concludes with a new gate keeping model that acknowledges individual gatekeepers working within a single institution, internal and external forces along the channels, and feedback.

Figure 3: Modern Gate keeping Model

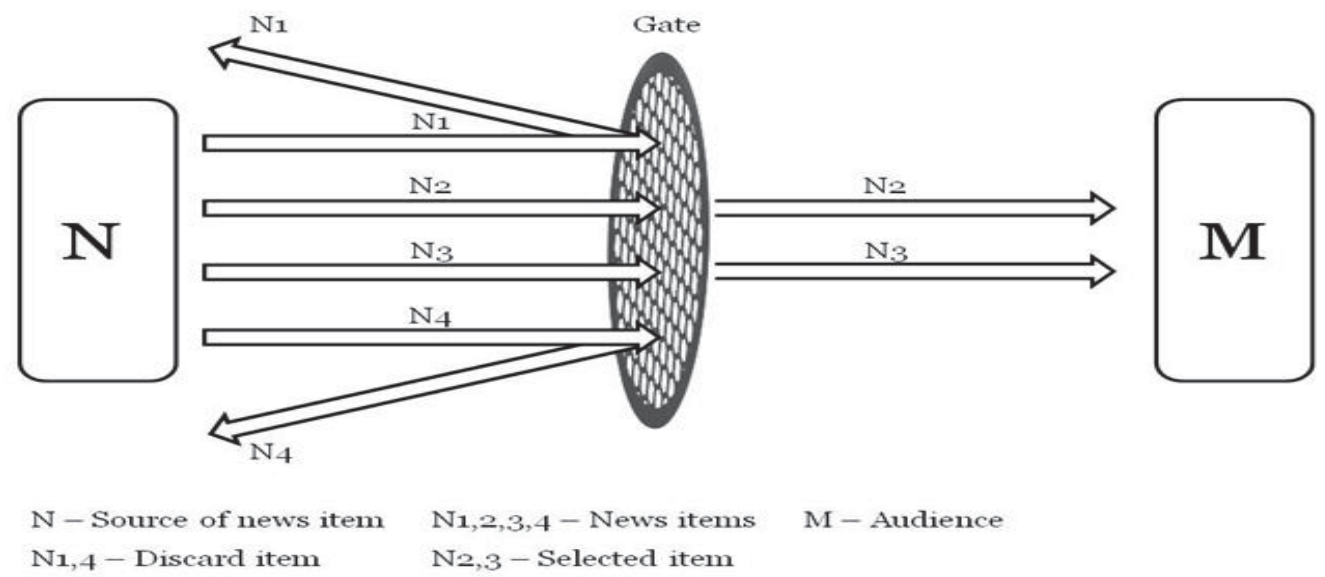

\section{Gate Keeping Theory}

\section{Reasons of Gate keeping}

Gate keeping is very important function of media, the channels and news papers have their own ethics and policies through this the editor decide the news items for publish or aired. Gate keeping occurs at all levels of the media structure, from a reporter deciding which sources are chosen to include in a story to editors deciding which stories are printed or covered, and includes media outlet owners and even advertisers. Individuals can also act as gatekeepers, deciding what information to include in an e-mail or in a blog. There are a lot of reasons of Gate keeping in a Pakistan or any other society of the world, this process helps in protecting ideology, norms, culture and dignity of any nation.

\subsection{A large amount of news}

Every news medium has a very large number of stories brought to its attention daily by reporters, wire services, and a variety of other sources.

\subsection{Limited amount of time or space}

Due to different practical concerns, only a limited amount of time or space is available in any medium.

The remaining space must be devoted to advertising and other content. Today, not only in Pakistan but all over the world, it is fact that every second of the electronic media and every line of print media are sold, many times a reporter has to cover everything in one minute story in T.V and few line news for print media. Then copy editor has to edit every explanation of the news because of shorter of time and space. 


\subsection{Criteria for judging particular news}

There always exists a news perspective within any organization that includes a complex set of criteria for judging a particular news story. This perspective is based on economic needs, organizational policy, newsworthiness, conceptions of the audience, and obligations of journalists. In my fifteen years career, I often had to cut out enormous part of the story. Media in Pakistan is also responsible about ethics and norms of society; we can publish or aired a story of rape with girl, but cannot notify the process of rape, have to hide the identity of a particular girl.

\subsection{Tastes of the audience}

Taste of the audience always vary in different societies, if take the case of Pakistan, the educated people always prefer to see or read the political and social news, laborers are want to see showbiz page and stage dramas, many people are interested in watching movies and dramas, so an editor or director news have to justify its selection according to the gratification of audience, that is way news about crime, showbiz, sports and politics are more popular in media, other stories not get required treatment.

\subsection{Every truth is not for publish or aired}

Sometimes there comes a very difficult task for a media person, when he has to conceal the truth from masses because of somebody personal identity, national integrity or national interest, in Pakistan we had faced a worst kind of terrorism, current government is working to overcome this issue, so media has to put out of sight the truth. It is unofficial advisory by all news organizations not to publish, telecast or broadcast news which could harm the process of dialogue between Government and Taliban.

\section{Levels of Media Gate keeping}

The gatekeeper's choices are a complex web of influences, preferences, motives and common values. Gate keeping is inevitable and in established circumstances it can be useful or dangerous, in this regard some levels should be maintained.

\subsection{Individuals}

Decisions are personal; journalist alone selects how the information gets sorted, no one asked him about the source of news, even if he hides some part of the news, even editor cannot do anything against him in this regard.

\subsection{Routine Practices of Communication Work}

Decisions are made according to a pre-established and generalized set of practices, ethics and policy of organization. Within an environment of media there are many other aspects that affect the gate keeping process.

\subsection{Social Institutions}

Events vary to a degree that they are culturally available as news items. Sponsors, contributors, advertisers and other external forces have a great influence in determining how the information should be organized.

\subsection{Societies or ldeology}

Culture, social values, political and pressure groups and ethnicity always, influenced selection criteria of news. News with least interest and importance could not get space or time. For example, in Pakistan, media hardly publishes, broadcasts or telecasts news about sex, nudity, factiousness, and ethnicity. Some institutions are respected, some are sacred cow. In recent years news against judiciary and armed forces only get space when persons are involves, otherwise it will be rejected, Malik Riaz allegations about the Ex chief justice of Pakistan's son cannot get due space and time. 


\section{Gate Keepers}

In Print Media First of All an individual is a gate keeper, than source, Assignment editor, reports or correspondents, sub editors, news editors and at last editor worked as gatekeeper. In Electronic media Same Pattern follow with a little bit changing, there is also an individual perform as a gatekeeper, than source, Assignment desk, reports or correspondents, copy editors, news editors, Producers, shift in charge, controller news, and at last Director news worked as gatekeeper. On every level every gate keeper not only follow the Policy of organization but also tend to impose his own agenda, by letting some news to go or not included in news paper and news bulletin.

\section{Conclusion}

Gate keeping is the vanilla ice cream of mass communication theories. It may not be Everyone's favorite, but nearly everyone can tolerate it. And while it may have an unremarkable flavor, it serves as a building block for other theory and methodological approaches. Media gate keeping showed that decision making is based on principles of news values, organizational routines, input structure and common sense. Gate keeping is vital in communication planning. It is can also be dangerous, since it can lead to an abuse of power by deciding what information to discard and what to let pass. Nevertheless, gate keeping is often a routine, guided by some set of standard questions. The gatekeeper's choices are a complex web of influences, preferences, motives and common values. Gate keeping is inevitable and in some circumstances it can be useful. The expansion to the internet has very much expanded the views regarding the gate keeping process, since any person or organization can publish anything in the way they see fit.

\section{References}

Stacks, D. W., \& Salwen, M. B. 2009. An integrated approach to communication theory and research. New York: Rout ledge.

Shoemaker, Pamela J.; Vos, Tim P. 2009. Gate keeping Theory. New York: Rout ledge.

DeFleur, Melvin; DeFleur, Margaret 2009. Mass Communication Theories: Explaining Origins, Processes, and Effects. Allyn \& Bacon.

Berkowitz, D .1990. "Refining the gate keeping metaphor for local television news," Journal of Broadcasting \& Electronic Media Vol. 34 No.(1)Pp.55-68.

Snider, P.B. 1967. "'Mr. Gates; revisited: A 1966 version of the 1949 case study," Journalism Quarterly Vol. 44 No.(3) Pp.419-427.

White, David Manning (1950). "The "gate keeper": A case study in the selection of news". Journalism Quarterly 27: 383-391.

Shoemaker, Pamela; Eichholz, Martin; Kim, Eunyi; Wrigley, Brenda (2001). "Individual and routine forces in gate keeping". Journalism \& Mass Communication Quarterly 78: 233-246.

Singer, Jane B. (2003). "Campaign contributions: Online newspaper coverage of Election 2000". Journalism and Mass Communication Quarterly 80: 39-56.

Lewin, Kurt (1947), "Frontiers in Group Dynamics," Human Relations, Vol. 1, No. 2,p.145

Park, Robert 1922. The Immigrant Press and Its Control. New York: Harper \& Brothers.

University of Twente, Gatekeeping, regulate the flow of information, 2014.retrieved from http://www.utwente.nl/cw/theorieenoverzicht /Theory\%20clusters/Media,\%20Culture\%20and\%20Society/gatekeeping/

Kalyanji Suresh (2003), journalism and mass communication chapter 3 Uses and effects of Mass Media..retrieved from http://www.peoi.org/Courses/Coursesen/mass/mass3.html

Kendyl Salcito (2014), Online Journalism Ethics, retrieved from http://www.journalismethics.info/online_journalism_ethics Igatekeeping.htm

Monica Stevens, Chorn, (2005). Journalist Gatekeeping responsibilities, retrieved from http://work.chron.com/journalist-gatekeeperresponsibilities-12377.html

Cima (2013), the New Gatekeepers: Controlling Information in the Internet Age. retrieved fromhttp://cima.ned.org/publications/newgatekeepers-controlling-information-internet-age.

Barzilai-Nahon, Karine (2008). "Toward a Theory of Network Gatekeeping: A Framework for Exploring Information Control". Journal of the American Information Science and Technology 59 (9): 1-20.

Communication theory, Gate keeping theory.2013.retrieved from http://communicationtheory.org/gatekeeping-theory/ 